\title{
Xavier Albó: Memoria, crónica y perfil
}

Guillermo Delgado-P.

University of California, Santa Cruz

\begin{abstract}
This article is a tribute that historicizes the initial impact and reception of Xavier Albo's foundational ideas in the establishment of social sciences in Bolivia. The author recalls Albó's academic interest in linguistics and ethnographic research and situates his influence in the context of the 1960s and 1970 s socio-political upheavals. He also sums up the setting to understand an early need to establish CIPCA, today a respected research center that has become a point of reference in the social sciences.

\section{Keywords}

Bolivian ethnography, CIPCA, Human Rights, indigenous languages, intellectual commitment, pluriculturality, Quechua linguistics, social change, social justice, social sciences research
\end{abstract}

\section{Resumen}

Este artículo es un homenaje que historiza el impacto inicial y la recepción de ideas fundacionales del antropólogo y lingüista Xavier Albó en el establecimiento de las ciencias sociales en Bolivia. El autor rememora el interés académico de Albó en la lingüística y la investigación etnográfica y sitúa su influencia en el contexto de los disturbios sociopolíticos de los años 
60 y 70 . También se recapitula un transfondo para entender la temprana necesidad de establecer CIPCA, hoy día un respetado centro de investigación que se ha convertido en punto de referencia para las ciencias sociales.

Palabras claves

Cambio social, CIPCA, compromiso del intelectual, Derechos Humanos, etnografía en Bolivia, idiomas indígenas, investigación en ciencias sociales, justicia social, lingüistica quechua, pluriculturalidad

\section{Introducción}

A Xavier Albó se le reconoce como a un prolífico investigador, humanista, antropólogo prematuramente inter-disciplinario, y también por ser un intelectual comprometido al modo gramsciano. Es y ha sido un fiel testigo de la Bolivia de la segunda mitad del siglo XX que, como él, extiende hacia el presente sus cualitativos cambios gestados para continuar mejorando la condición social de la población aminorada de la nación. Estamos hablando de un solidario y versátil militante 'orgánico' que en su pensamiento y obra académica abstrae críticamente desde la realidad vivida. Su vida intelectual constituye un paralelo que centra su pasión tanto escolástica como humana en el histórico sujeto del indianismo. Retornando a Gramsci, quien afirmó que no hay un homo faber sin un homo sapiens, pienso que Xavier Albó llegó a perfeccionar en vice-versa la transición entre uno y otro estado.

\section{Memoria 1}

En este artículo de homenaje a la obra de Xavier Albó que se celebró en LASA-Barcelona 2018, la sesión titulada: "The Life Work of Xavier Albó: His Enduring Contribution to the Founding of Social Science in Bolivia" (May 2326), mi propósito ha de ser el de retrotraer, desde hoy, la temprana influencia de Xavier en el estudiante de colegio que fui al finalizar los años sesenta. La perspectiva tiene dos momentos: uno, mi memoria de su obra inicial y, dos, la reflexión que de esa memoria tengo desde este presente. Digo esto porque pertenecemos a generaciones diferentes, aunque muy cercanas $y$, aquí, es importante tomar en consideración aquellas convulsionadas décadas que constituyeron su trasfondo, porque desde ellas se puede elogiar el rico legado intelectual y humano de Albó. Naturalmente, la temporalidad que narro en este homenaje ya ha sido afectada por el presente, es decir, me permite 
reconstruir una secuencia del pasado, esta memoria, desde las tantas lecturas hechas en todo este tiempo vital y académico que me traen al hoy en día.

Pertenezco a la generación afectada por los grandes cambios de esos años sesenta, aquello que el periodista español Manuel Vázquez Montalbán identificó con "los hijos [e hijas] de aquel encuentro mágico entre Marx y Rimbaud soñado en todos los mayos de los años sesenta: cambiar la Vida, cambiar la Historia". Xavier salía de Bolivia en 1961 y retornaba para 1969, en cambio yo salía de Bolivia en 1968, y retorné al país ya sólo esporádicamente. Xavier ya era un formado antropólogo cuando yo comenzaba la propedéutica en la Universidad Católica de Santiago en 1969. Sin embargo, ya había sido expuesto a su obra primaria, que constituía en valorar el quechua desde la sociolingüística como un complejo lingüístico-antropológico vivo. Esa influencia suya me acompañaría siempre.

Con la pretensión de ubicar a Xavier Albó en ese itinerario de interrupciones y altibajos de la política boliviana, es importante recordar que la idea de establecer la práctica antropológica, o de las ciencias sociales en Bolivia nunca fue fácil, ni gratuita. Establecerlas tomó la convicción de varias generaciones, muchas asediadas o exiliadas debido a su vital compromiso con las ciencias sociales. Hasta aquel momento de los años sesenta, el indigenismo estatal e integracionista estaba liderizado por funcionarios no-indígenas y el temprano trabajo de Xavier Albó ya puede situarse en el espacio que invalida como anacrónico, texto y subtexto de dicho indigenismo. Mientras Xavier blandía sus primeras armas intelectuales en Bolivia como acompañando, cual testigo ocular, las grandes transformaciones que traía la tempranamente aletargada Revolución Boliviana de 1952, la dignidad quechua le habría afectado en demasía porque, una década después, optó por ausentarse del país (1961) a estudiar sociolingüística y antropología en la Universidad de Cornell para precisamente auscultar y sistematizar un área que hasta aquel momento era sitio privilegiado de dispersos investigadores extranjeros cuyos trabajos rara vez circulaban entre nacionales, menos aún en traducciones.

Mi relación con Xavier Albó siempre fue a través de la lectura de su eximia obra antropológica y sociolingüística, cruzamos diálogos pocas veces. No obstante, inevitable, surge él en las conversaciones con otros coetáneos como Kevin Healy, Silvia Rivera Cusicanqui, Cecilia Salazar de la Torre, Edgardo Vásquez Tapia, Ixs periodistas de Aquí, Sonia Dávila Poblete, Josefa Salmón, Víctor Hugo Cárdenas, Carlos Toranzo y tantxs otrxs colegas. Así, a Xavier se le reconoce por ser el promotor de los estudios sociolingüísticos en Bolivia y especialmente el de ser un sistemático estudioso de las lenguas indígenas. 
Luego, es imposible concebir la historia de las ciencias sociales de Bolivia sin la fundante contribución que estableció Xavier al conceptualizar y dirigir CIPCA, el Centro de Investigación y Promoción del Campesinado, afirmando con ello su compromiso humanista a través de la sostenida emisión de estudios consagrados que reposicionaron al sujeto indígena del país desde una perspectiva émica, sobre todo del quechua y el aymara y, luego, al fomentar los estudios antropológicos sobre todas las poblaciones indígenas desde una necesaria interdisciplinariedad, siguiendo la tradición latinoamericana.

Recordemos que Claude Lévi-Strauss estuvo en Santa Cruz de la Sierra y Cochabamba en 1938, recogiendo datos para escribir su famoso Tristes Tropiques; que el minesotano Allan R. Holmberg, etnógrafo que en 1940 documentó a los sirionó, habría muerto afectado por una enfermedad tropical recogida en la Amazonía, y la austriaca-paraguaya Wanda Hanke, ambos antropólogos con visiones casi contradictorias, incursionaban en la etnográfica pasión por documentar las tribulaciones de las sociedades nómadas que habitan de antaño la Amazonía. No fueron los primeros, no son los últimos. Mientras Holmberg quería entender el impacto de la emaciación entre los sirionó y documentar el 'cambio social', a menudo introduciendo indirectamente 'tecnologías occidentales', Wanda Hanke, afectada ya por un compromiso con el emergente concepto de los Derechos Humanos (1948), hallaba a su paso indígenas esclavizados por los rancheros benianos y cruceños, y trabajaba para denunciar a estos alevosos, muy posiblemente afectada en su sentimiento antropológico por los desmanes colonialistas de tan notable crueldad en Africa y, sin ir tan lejos, por "la banalidad del mal" de la que escribe Hanna Arendt en referencia al nazismo alemán y al fascismo italiano. Hanke había detectado una evidente situación de ilotismo y lejos de etnografiar el cambio social entre aislados nómadas entraba, precozmente, en el espacio del concepto de los Derechos Humanos. En cambio, Holmberg, hacia el final de su obra, declara su mea culpa al concluir que mejor no hubiera intentado provocar ni evaluar cambio social alguno, que hubiera sido mejor dejar a los sirionó en paz y tranquilidad. Los años sesenta trajeron también un libro escrito en inglés sobre los aymara, por William Carter (1964), que mucho después fue director de la Sección Hispana de la Biblioteca del Congreso en Washington, DC., era el único texto que, tras veintisiete ediciones, informaba a los lectores en otras latitudes acerca de una especie de identidad aymara congelada.

Estos aislados estudios etnográficos, los de Holmberg, Hanke, o Carter, proyectaron una otredad radical de aquellos tiempos, la imagen de la indigeneidad amazónica o andina de "sociedades frías", ante generaciones de 
lectores euro-estadounidenses que por primera vez escuchaban que la presencia de la "civilización occidental" no constituía sino un inevitable accidente, "una civilización accidental" centrada en la apropiación de la fuerza de trabajo de nómadas inducidos a un sedentarismo forzado, eufemismo de la esclavitud, o campesinos indígenas que, debido a la media implementada reforma agraria, se liberaban del pongueaje y el sistema de la hacienda. La supervivencia de estas poblaciones que mantuvieron su propia temporalidad sólo podía disciplinarse a través de un capitalismo de rancho, un simulacro distorsionado del cambio social. La etnografía de la época vio en la Amazonía y el altiplano andino a los sobrevivientes de sociedades que se pensaron extintas, ahora doblemente asediadas por el proselitismo protestante, los inevitables misioneros de toda procedencia, la extracción de la fuerza de trabajo sin salario, y la cada vez más vigente urbanización de esas áreas afectadas por evidentes procesos de despojo territorial a pesar de la reforma agraria de 1952. En razón de la extensión del ganado y la lenta pero sostenida desforestación incremental, entrábamos a contemplar de lleno la transformación de la Amazonía en hamburguesas, en la que el capitalismo local rediseñaba el mismo territorio con propósitos devastadores. $Y$ en el altiplano se aceleraban procesos migratorios de los antiguos ayllus rurales, muchos afectados por sequías extensas, hacia la urbanización de El Alto de La Paz, hoy toda una ciudad.

La antropología nacional hasta esa época le pertenecía casi en propiedad a ciertos nombres y entidades tales como las Sociedades Geográficas, algunos 'científicos' que alentaron revistas como Khana, La Gaceta Campesina, Pumapunku, Estudios Andinos, Cultura Boliviana, Revista Canata, Letras Bolivianas, y otras de corta vida. Ausente, a menudo, estaba la representación indígena, y la formalidad académica de la materia estaba traslapada (cuando existía) bajo los estudios de las llamadas "ciencias jurídicas y sociales", más como una materia complementaria que como una disciplina. De lo contrario, no era sino una práctica folklorológica, taxonómica, o arqueológica, centrada en el "enigma" de Tiwanaku (Carlos Ponce Sanjinés) o la seriedad con que se organizaba el Museo Arqueológico de Cochabamba (Geraldine Byrne de Caballero), que se constituiría en un centro neurálgico de una arqueología regional, de historia natural, relacionada con la presencia inca en la región. Naturalmente, como obra aislada, Ramiro Condarco Morales dialogaba con sus congéneres peruanos o argentinos, y John V. Murra, mucho, mucho después, reconocería la contribución intelectual de Condarco Morales entre los estudiosos andinos de esa generación. 


\section{Crónica 1}

Mientras tanto, quienes se interesaban en los idiomas indígenas se concentraron en acopiar primero léxicos y diccionarios, tratando de compilar una especie de registro lingüístico del quechua y del aymara, lo que Alberto Escobar llamó, en la Presentación al libro de Xavier: "la reconstrucción histórica de sus fases previas" (1974). Sólo hoy sabemos que hubo voces discordantes que reposicionaron el pensamiento indígena, voces nativas que articulaban justas demandas ante un público reducido aun cuando no se los asocia con la antropología emergente de aquel entonces. Pensemos en Jesús Lara, Fausto Reynaga, en el peruano César Guardia Mayorga, Elizardo Pérez, en los tempranos "indianistas" y militantes aymaras que articularon el primer MITKA, ${ }^{1}$ la lenta emergencia indianista del Katarismo (e.g. MINK'A) y, luego, el persistente y fundante trabajo del THOA, Taller de Historia Oral Andina en cuyo subtexto emerge la influencia académica de Xavier Albó.

Aquella solemne formalidad exclusionaria y distante de lo que hoy llamamos la indigeneidad, habría de resquebrajarse ante la emergente nueva antropología y la sociolingüística. La tangible recomposición demográfica de estas poblaciones y la admirable persistencia de lenguajes indígenas, que se arrastraban en el espacio público desde la Conquista, demandaba repensar la agenda académica. Tras haberse firmado la Primera Declaración de Barbados (1971) que se llamó "Por la liberación del indígena", un giro descolonizador de desafiantes antropólogos tanto latinoamericanos como europeos planteaba tempranamente un cambio de perspectivas que implicaba el compromiso directo, el diálogo, con quienes eran objeto de estudios. Xavier teorizó tempranamente la realidad marginal de esas lenguas, apuntando que: "La opresión social fomenta el doble monolingüismo y éste a su vez garantiza la persistencia de la opresión" $(1974,224)$. Porque quienes practicaron la etnografía hasta aquel momento, salvo excepciones, (e.g. lingüistas comprometidxs con el estudio formal de las lenguas indígenas como Martha Hardman, de la Universidad de Florida, Louisa Stark en Wisconsin o Yolanda Lastra en Cornell), tenían un enfoque formalista, afectado del estructuralismo de la época, hacia los "estudios de caso" apoyados en el relativismo cultural, aunque circunscritos a las fluctuaciones y afectos de las lenguas vivas en contacto. Sus contribuciones devinieron fundantes y

\footnotetext{
1 Casi dos décadas después, Pedro Portugal Mollinedo, director del Centro Chitakolla reconstruye este origen en "Una experiencia de organización política india" (1989).
} 
necesarias porque simplemente no existían materiales confiables ni organizados que hubieran reactualizado y sistematizado las preocupaciones legadas desde el horizonte colonial (e.g. González Holguín, Bertonio, Mosi, De Torres Rubio). La lingüística y la sociolingüística emergían con proposiciones sistematizadoras y actualizadoras de problemáticas clásicas.

Alternamente, quienes documentaban con pasión de dedicados lexicólogos habrían reconocido el valor que tenía la emisión activa de lenguajes que no desaparecían, la oralitura, contribuyendo, a menudo, a proponer e implementar políticas educacionales. ${ }^{2}$ Vale la pena recordar de aquellos años sesenta, quizá provocados por el rol que tuvo el quechuólogo y escritor Jesús Lara, ${ }^{3}$ a otros comprometidos académicos de la talla de Jorge Urioste y Joaquín Herrero, Enrique Oblitas Poblete, Yolanda Lastra, Luis Morató Peña, Erasmo Tarifa y Felicia Segovia, que trabajó cercanamente a Louisa Stark, todos disciplinados y comprometidamente centrados en considerar las lenguas indígenas materia de investigación, documentación, proyectando la formación de críticos investigadores y pedagogos. Entre ellos aparece Juan de Dios Yapita, colaborador de la lingüista Martha Hardman y, en Cochabamba, Urioste y Herrero, que con el patrocinio, asumo, del Instituto de Idiomas de la Maryknoll Society, publican textos didácticos, diccionarios y gramáticas centrados en la enseñanza del aymara y quechua. ${ }^{4}$

Antes, sin embargo, ya Xavier publicó para 1964 su original texto titulado El quechua a su alcance, patrocinado por los fondos de la Alianza para el Progreso. Visto desde la perspectiva de un estudiante de secundaria que fui en esa época, Xavier estaba inmerso en un periodo productivo e inicial, como llevando a la práctica simultánea las lecciones absorbidas en la Universidad de Cornell. Esas lecciones, para formalizarlas en concreto, necesitaban no sólo de escribir una gramática, o la de abordar la sociolingüística quechua,

\footnotetext{
2 Años después, Eduardo Nogales Guzmán, en 1994, registra un programa titulado "Yuyay jap'ina", Alfabetización intercultural y bilingüe para la mujer andina, patrocinado por FIS/UNICEF, con precisa extensión sobre las zonas quechuas.

3 Para aquella época se publicaron: Sinchikay (Buenos Aires, 1962) y Llalliypacha (Buenos Aires, 1965). Los títulos en quechua anunciaban un reposicionamiento literario ajeno a la narrativa urbana, quizá más proximo a la obra de José María Arguedas. César Guardia Mayorga exploraba el tema del quechua en la UMSS de Cochabamba.

4 Para 1955, Urioste y Herrero escribieron Gramática de la lengua quechua y, en 1974, Xavier Albó surge con Los mil rostros del quechua. Sociolingüística de Cochabamba. Este libro, como toda obra de Xavier, es un estudio riquísimo, sus notas de pie constituyen toda una historia paralela del quechua de ese periodo.
} 
sino la de fundar una institución dedicada al trabajo académico. ¿Qué pasó? Hasta ese momento no existía en Bolivia un estudio o catálogo formal de las lenguas que se hablaban en el país. Hubo intentos aislados y entusiasmados, aunque siempre con la intención de 'aculturar' a quienes aun reconocían herencias precolombinas. Era el caso del desafortunado Instituto Lingüístico de Verano, cuyas raíces en el fundamentalismo protestante del Deep South estadounidense veía en las poblaciones indígenas sólo apóstatas y contumacia, era como estar en el siglo XVI. Cuando el antropólogo cubano Fernando Ortiz ya hablaba de la "transculturación" (1940), Holmberg todavía recoge esa palabra "aculturar", concepto que asume la amnesia lingüística-cultural o la autonegación. En la práctica, era una propuesta asimilacionista, de teleología unidireccional, ignorante de las diferentes temporalidades, ontologías, y conceptos de espacio y tiempo que transmitía el ejercicio público de las lenguas indígenas en condiciones de exclusión.

Con la participación de Xavier Albó, la sociolingüística formal y la renovación de las aproximaciones etnográficas a través de los estudios mimeografiados en Cuadernos de Investigación CIPCA constituyeron un evidente diálogo académico con los antes mencionados trabajos. Fue Xavier quien implementaría por vez primera el acceso a la computación para estimar precisiones y fluctuaciones fonéticas y fonémicas del emisor lingüístico de su tema, el quechua. Por necesidad, CIPCA se transformó, a mi manera de ver, en un modelo que giraba su mirada hacia estructuras lingüísticas subyacentes y ontológicas, allá se pondría en acción, directa o indirectamente, una agenda relativa a la etnogénesis de los movimientos sociales indígenas. Aclaremos que en Perú ya existía una institución que poco a poco se daba a conocer con su producción académica, el Instituto de Estudios Peruanos (fundado en 1964), y se notaba la emergencia de la revista de antropología Allpanchis Phuturinqa en 1969, bajo el auspicio del IPA (Instituto Pastoral Andina). No era un accidente, pues ese giro estaba inspirado, directa o indirectamente, por José María Arguedas, el antropólogo, escritor y quechuista que, infelizmente, se suicidó en $1969 .^{5}$

\footnotetext{
${ }^{5}$ En Santiago, a mí me impactó en demasía la presencia de José María Arguedas cantando a capella en quechua "Tampupampino mask'aspa", en los estudios de grabación de la Universidad de Chile, bajo el auspicio del poeta Pedro Lastra, amigo de Arguedas y director de Editorial Universitaria a comienzos de 1969. En esa misma escena Arguedas narró su inolvidable cuento "El sueño del Pongo". Hacia el final de los años 90, a instancias de Norma Klahn, mi esposa, ex-alumna de Pedro Lastra en SUNY-Stony Brook, fuimos a
} 
Quisiera imaginarme que Xavier retornaba a Bolivia, en 1969, con el doctorado en antropología en las manos para armar aquel necesario pero ausente centro de investigaciones que la contraparte peruana había ya sólidamente construido. Para entonces, ya readaptaba su tesis doctoral (1969) transformándola en el libro que tituló Los mil rostros del quechua (Lima, 1974). A los ojos de hoy, además de su rigor académico, que es todo un paradigma metodológico de aquel momento augural, su libro constituye una historia del mismo quechua en la década de los años sesenta.

Notemos que la palabra "campesinado" recogía todavía el contagio ideológico del nacionalismo revolucionario, y el indianismo se iba gestando a medida que aparecía como un contradiscurso en la esfera pública. Para Bolivia, CIPCA constituyó aquel primer espacio donde Ixs interesadxs en las ciencias sociales del país se convocaban para asegurar una continuidad institucional formalizando y ordenando las características de un centro de investigaciones en ciencias sociales que tuviera un programa sobre un sujeto importante del país como son las sociedades indígenas. Sin desmerecer, naturalmente, hubo otras empresas de corta vida, quizá materia que habría que recuperar para el registro histórico. CIPCA tiene paralelos dolorosos con las intenciones de varixs académicxs que vieron la necesidad de crear, sustentar y mantener la continuidad (siempre difícil) de cualquier centro de investigación. Recordemos que en esa misma época don Gunnar Mendoza sentaba pacientemente las bases para consolidar el ahora respetado Archivo Nacional de Sucre. En Potosí, recuerdo a don Mario Chacón, que en esas mismas épocas luchaba por continuar la organización de los respectivos repositorios. De todos ellos, y de los que les antecedieron, se pudo decir, repitiendo la Canción de los Mineros: "avanzan a paso lento, pero en forma agitada". ${ }^{6}$

Así, CIPCA, a mi parecer, se transformó visiblemente en el punto de referencia de la renovada academia nacional, la academia que, con

\footnotetext{
visitarle y volví a rememorar esta histoia en su casa. Pedro recordaba ese momento con la claridad de ayer, a pesar de los 25 años de por medio. Estando en Santiago también tuve la oportunidad de conocer a Paulo Freire, que circulaba capítulos sueltos de su Educação como prática da liberdade, y conducía cursos de concientização para adultos articulando su Pedagogía del oprimido. Entre otros exiliados brasileños, profesores nuestros en la Universidad, estaban Fernando Henrique Cardoso y Francisco Weffort, uno de los fundadores del PT brasileño.

${ }^{6}$ Es importante anotar que en 1961 el porcentaje de analfabetos era del 82\%, había 5,295 escuelas rurales con 7,190 maestrxs. El promedio de médicos era de 5 por 20.000 habitantes. Había 284 enfermeras, 67 parteras y 895 médicos registrados (Ribera de la Souchère 1968, 44).
} 
anterioridad, se habría estancado en anacrónicas conceptualizaciones evolucionistas sino social darwinistas, curiosidades extranjeras o anticuarios, especialmente de las sociedades andinas y sus supervivientes lenguajes. Esas culturas indígenas aparecían sabias y coherentes en los estudios arqueológicos, sus herederxs, empero, todavía respiran en los Andes, provocando la necesidad de una antropología actualizada, un aggiornamento para la comprensión de un longue durée.

Es importante aquí no subestimar a la generación de investigadores anteriores a los años sesenta, bolivianxs que alentaron la aproximación académica a los estudios andinos y las lenguas indígenas, muchxs partícipes de esos logros, tempranamente motivadxs en entender las dinámicas del cambio social y, naturalmente, la mirada hacia comunidades que salían de la experiencia de la reforma agraria boliviana de 1952. De hecho, Xavier Albó apunta con precisión ese momento: “Durante la última década [1960s] la investigación sobre el quechua, y en menor grado sobre otros idiomas andinos, se ha intensificado hasta el punto de contar desde 1970 con un boletín periódico informativo sobre nuevos desarrollos en este campo y, desde 1972, una revista con artículos dedicados exclusivamente a la lingüística andina" $(1974,15)$. Sin duda que Xavier Albó respondía así a una evidente necesidad, siguiendo la tradición jesuítica de comunicarse con los neófitos en su lengua. Recordemos que, en el Siglo XVIII, los guaraní se rebelaron contra los dominicos poco después de la expulsión de los jesuitas de las misiones del Alto Paraguay sólo porque los dominicos que sustituirían a los previos no hablaban guaraní. Saltando en el tiempo, el contexto de los años sesenta articulaba la emergencia de preocupaciones epistemólogicas del momento: las teorías de la modernización, el estructuralismo ahistórico, el cambio social, la pedagogía del oprimido, la teoría de la dependencia. ¿Cómo "integrar" a la forma nación a persistentes hablantes de lenguajes estructuralmente ajenos al castellano? ¿Cómo entender el nuevo momento o proceso de agnición de ese periodo? ¿Continuar oprimiendo a Ixs hablantes de lenguajes aglutinativos, y castellanizarlos, ó, respetar sus visiones de mundo, "sus estructuras profundas, sus propias ontologías y temporalidades"?

\section{Memoria 2}

Pero las cosas no fueron tan fáciles como parecieran. La década de los años 60 en Bolivia se fue transformando en una década infame. Grandes políticas externas que llegaban al país como novedades traían, no tan 
escondida, esa misión evidentemente intervencionista de la Alianza para el Progreso, política desarrollista estadounidense cuyo objetivo era contrarestar el ímpetu de la Revolución Cubana de 1959, ofreciendo como modelo alterno la portoriqueñización (desarrollo cosmético y consumo clasemediero) de América Latina, eufemismo de un neocolonialismo que expresaba su tensión en la emergencia contestataria de la guerrilla. Elena Ribera de la Souchère, periodista catalana observadora de la política latinoamericana escribía, en febrero de 1968: "Bolivia es hoy, como antes, el laboratorio de experiencias de las grandes corrientes políticas de A.L. Después de haber sido el teatro de la más radical de las revoluciones nacionalistas, y luego de la caída del régimen revolucionario bajo los golpes de una coalición de partidos extremos, es hoy el lugar en que se enfrentan con el más alto grado de tensión y de evidencia las dos tesis de la izquierda latinoamericana: la guerrilla revolucionaria y el frente único de las fuerzas progresistas" (1968, 50).

Un repaso cronológico de esa época resume el intríngulis que ilustra Ribera de la Souchère: Estados Unidos, una amenazante penumbra en el éter político, incursiona en 1962 con su política exterior titulada Alianza para el Progreso; en 1964 estalla un golpe de estado contra el decantado MNR; surge un militarismo funcional a los intereses imperialistas; el general golpista René Barrientos se dirigía a la gente rural en quechua. Que alguien utilizara el quechua para comunicarse con los habitantes de las áreas rurales a través de discursos populistas dejó un halo curioso y provocó un despiste cultural del nacionalismo. ${ }^{7}$ Hubo una masacre de mineros que se llamó La Noche de San Juan (en reacción, un poeta dice: "me preguntan/ si el estaño boliviano/se vende más/cuando en sangre está bañado"). En 1967 fuimos testigos afectados por la presencia guerrillera del Che, que puso a Bolivia al centro mismo de la atención mundial. El mismo año circulan copias mimeografiadas de La Teología de la Liberación de Gustavo Gutiérrez; los sacerdotes de ISAL se radicalizan y surge el concepto de una "revolución cultural". ${ }^{8}$ En 1969, el militar golpista Barrientos (al que en la embajada americana se le conocía como "our boy"-el tilde no esconde una subestimación racial) muere calcinado en un accidente de helicóptero; y en 1970 emerge una Asamblea Popular, de corta vida. Ante la dualidad de poderes, el general izquierdista Juan José Torres es derrocado en el

\footnotetext{
${ }^{7}$ Xavier recoge e interpreta el caso en Los mil rostros del quechua (88-89).

8 Ver Ivan Illich, Bolivia y la revolución cultural (1970).
} 
contragolpe fascista del 21 de agosto de 1971. Mauricio LeFebvre, sociólogo y sacerdote Oblato, es asesinado en las calles; la alevosía autoritaria del momento se transforma en sevicia. Hay exilios y se impone una ley marcial. Esa nueva modalidad represiva se extiende en la eliminación física e impune de militantes de la izquierda. La extensión regional de la aún secreta Operación Cóndor, patrocinada por la CIA, entra en vigencia junto a la nueva palabra: "geopolítica". Este es un escenario inmerso en el clímax mismo de la Guerra Fría, las crudas tensiones del Este y el Oeste se viven en Bolivia a flor de piel. ${ }^{9}$

América Latina estaba sistemáticamente militarizada. El ímpetu de las transformaciones sociales tan brillantemente teorizadas por René Zavaleta Mercado, que fue actor y testigo ocular de ese periodo entra en una especie de desorientación y cansancio. Ribera de la Souchère resume el nadir de esta manera: "Una generación que se ha salteado siete siglos de historia en diez años (1952-1962), llenos de tumultos de batallas y de desfiles, ya no tiene probablemente una fuerza de reinvindicación suficientemente intacta para abordar una nueva etapa". ${ }^{10}$

En medio de exilios y persecuciones, unos años antes, sin embargo, posiblemente entre 1965 y 1966, Rodolfo Kusch llegó de la Argentina a Bolivia con el objeto de estudiar "la filosofía popular" ligada a la preservación y ejecución lingüística de otros idiomas diferentes del castellano. La presencia de Kusch, quien habría recuperado a José Imbelloni en la Argentina y leído Los imperios andinos de José Fellman Velarde, temprano estudioso de las filosofías indígenas (las llamaban "enigmas", "pensamiento andino"), alentó a los escasos estudiosos locales e inculcó cierta aura académica privilegiando el nomos de las culturas andinas desde su protohistoria. Proponía Kusch una relectura de los ritos quechuas, de la interculturalidad, de la economía cualitativa, de los circuitos existenciales, de la reculturalización, pero, sobre todo, condujo sostenido trabajo de campo. ${ }^{11}$ Hubo más o menos en la misma

\footnotetext{
${ }^{9}$ Agradezco los extensos diálogos que sostuve con Loyola Guzmán L, militante, ideóloga, protagonista y testigo fiel de este periodo. Agradezco también a Edgardo Vasquez Tapia, Secretario Ejecutivo de la Federación de Trabajadores de la Prensa (La Paz, agosto 2018).

${ }^{10}$ El crítico Evelio Echeverría decía que "Si es cierto que la narrativa es la hija de la historia, tanto más lo ha de ser en Bolivia" ("Un pueblo en guerra: La narrativa boliviana de 1960 a 1970" 159).

${ }^{11}$ Rodolfo Kusch estuvo unido al Proyecto Waykhuli (Valle Alto de Cochabamba) de desarrollo de comunidades "Ayni Ruway", inspirado en "la reconstrucción del ayllu" como una propuesta de revalorización de lo nativo, un tema que también inspiró a Hugo Romero Bedregal y otrxs. El concepto de "reculturalización" acuñado por Kusch sugería entender una ontología hilozoista quechua.
} 
época otras dos personas que, vistas desde la memoria de hoy, habrían legado cierta herencia antropólogica. Me refiero a Verónica Cereceda y Gabriel Martínez Soto-Aguilar, que se dedicaban a sistematizar una aproximación antropológica hacia el quechua, el aymara, el simbolismo de los tejidos andinos y el teatro oral, desde la Universidad Técnica de Oruro. Se notaba que ambos estaban influidos por las nuevas aproximaciones etnográficas inspiradas en el estructuralismo francés, la semiótica y el simbolismo, aunque también en una especie de compromiso paralelo con la conservación y promoción de la lengua y la cultura material andina de quienes se etnografiaba, como era el caso de Kusch, además de una precoz aproximación ya ecológica. ${ }^{12}$

\section{Crónica 2}

Siendo aún un estudiante de secundaria en ese tiempo, asistí a una presentación teatral en quechua con actores indígenas, tanto hombres como mujeres, en la sala principal del segundo piso de la Universidad Técnica de Oruro. Verónica, vistiendo un poncho de Charazani, fungió de directora del Teatro Nacional Kollasuyu y presentaba una obra titulada “¿Mayta Purisanchej?"13 Casi coincidente con la emisión de Yawar Mallku de Jorge Sanjinés (1967), el tema de ambas obras se centra sobre dos temporalidades asintóticas, incluido el desencuentro entre el quechua y el castellano. Prueba de ello es que Yawar Mallku no se proyectó en Bolivia sino hasta mucho después, cuando la película fue reconocida en Europa como una obra maestra del cine latinoamericano. La tensión cultural y lingüística es notable en ambas obras, que proféticamente sitúan las herencias étnicas que empujaban los cambios que se demandaban con la introducción de las redefiniciones revolucionarias. La obra del Teatro Nacional Kollasuyo tuvo su audiencia, mayormente estudiantes, y se mantuvo en cartelera por algún tiempo, aunque el aire de represión nos soliviantaba.

\footnotetext{
12 Un estudio poco conocido de Gabriel Martínez Soto-Aguilar conducido en 1970 documenta la supervivencia aymara en el altiplano chileno colindante con Bolivia (Introducción a Isluga, 1975). Por su parte, y mucho después, Verónica Cereceda participa con su estudio seminal "Aproximaciones a una estética andina: de la belleza al Tinku", en el libro compilado por Thérèse Bouysse-Cassagne, Olivia Harris, Tristan Platt y Verónica Cereceda, Tres reflexiones sobre el pensamiento andino (1987).
}

${ }^{13} \mathrm{El}$ hecho está registrado por Xavier Albó en Los mil rostros del quechua (107-109). 
Para mí, en esa época, ver actores quechuas que expresaban sus ideas y sentimientos sin mayor problema, en su propia lengua, fue un gran aliciente intelectual porque, en casa, mis padres abrigaron un respeto político-cultural hacia lo quechua y lo aymara, ${ }^{14}$ lenguas que se hablaban porque eran sistemas lingüísticos de transacción diaria en los mercados públicos, los negocios de la ciudad y los campamentos mineros cuyos trabajadores, en sus mitas de veinticuatreo, las mantenían como lenguaje de comunicación. Sin embargo, un ambiente de opresión circundaba cohartando la libre expresión en esas lenguas $y$, aun así, latían conectadas a una historia andina mucho más profunda que la del allegado castellano.

Intuitivamente, algunos estudiantes de secundaria tratamos de intervenir en los medios de comunicación revalidando la escritura del quechua como una lengua activa, viva, naturalmente estimulados por las transmisiones radiales que llegaban del sur del Perú y algunas radios locales que transmitían en quechua a tempranas horas de la mañana o tarde de la noche. El folklore emitía a través de sus intérpretes canciones en quechua, y varios grupos folklóricos del norte argentino adoptaban nombres y palabras del quechua para nombrarse o incluirlos en los versos de sus canciones: Los Cantores de Quilla Huasi, la canción Chakaymanta; Las voces del Huayra, Atahualpa Yupanqui, dialogando con los "indigenistas" como Los Wara Wara, Los Jairas, Los Ch'askas, y la grabación de cantantes tanto en quechua como en aymara, varios ejecutando en tropas de sikuris como el Conjunto de zampoñas "Korimaqtas" en Oruro o los Qantus de Charazani. Algo pasaba en el ambiente local y las tecnologías de reproducción comenzaban a extenderse, grabando y públicamente transmitiendo a intérpretes y cantantes del Norte de Potosí, donde el quechua y el aymara mantienen una antigua y cálida presencia.

Por esos años Los Jairas, conjunto musical que cantaba en quechua y aymara, extendía sus melodías en el éter nacional. Tres de sus integrantes son bolivianos, Alfredo Domínguez, Eduardo 'Yayo' Joffré y Ernesto Cavour, reconocidos artistas que fundaron el 'neo-folklore andino' que adoptó entre sus instrumentos de ejecución las zampoñas, la quena, el bombo, el charango,

\footnotetext{
14 La pequeña biblioteca de mi padre acopió todas las obras del quechuista Jesús Lara y yo mismo estaba muy consciente del quechua que se hablaba en la representación de $L a$ Danza de los Incas, todos los lunes de carnaval en Oruro, danza que mis padres, de niños, habían presenciado en el Norte de Potosí, en Chayanta, Aymaya y Oruro. Mucho después, Nathan Wachtel retomaría el tema para escribir su libro La Vision des Vaincus, en 1971, traducido en 1976 como Los Vencidos. Los indios del Perú frente a la conquista española (1530-1570).
} 
guitarras y los cantos en aymara y quechua. El cuarto integrante es Gilbert Favré, un suizo que ejecutaba la quena y que habría llegado a Bolivia a través de Chile, habiendo trabado una relación romántica con Violeta Parra, la folkloróloga chilena. Una 'peña folklórica' los acogía en La Paz, también de nombre aymara, 'Nayra'. Si mal no recuerdo, Los Jairas debutaron nada menos que en el Teatro Municipal, supe, ante la desaprobación de cierta clase social en La Paz que se quejaba de que se tocaran instrumentos nativos y se cantara en quechua y en aymara -ien tan sacro lugar! Se asumía que ese Teatro estaba reservado para las óperas, música clásica y, por algún despistado favor, una banda militar que ejecutara marchas de aire áulico y teutón de tanta preferencia de las dictaduras (era la música de fondo para anunciar edictos militares, el estado sitio y el toque de queda).

Sin embargo, ante el rotundo triunfo de Los Jairas, el próximo paso era, naturalmente, una gira en Europa. ${ }^{15}$ Allá llegaron vistiendo atuendo indígena, ponchos tejidos y multicolores, monteras, lluch'us y sombreros de las regiones quechuas y aymaras. Además, cantaban en "esos idiomas" que en Europa se pensaban ya extintos. ¿Todavía habían indixs en Bolivia? ¿En las Américas? La pregunta surgió ante la lívida reacción de un embajador boliviano en una capital europea que, por la novedosa presencia de Los Jairas, habría tratado de negar su asociación con el país al decir que: "ahora van a pensar que Bolivia es un país de indios". ${ }^{16}$

¿Qué había pasado? Aquellas tecnologías de reproducción comunicativa incursionaban y expandían el espacio público: la explosión de radios de onda corta que transmitían en lenguas indígenas, la oferta de "pick ups" y discos LP 33 y $45 \mathrm{rpm}$, impresos en vinilo al alcance de cualquier bolsillo, la lenta llegada de cintas de grabación y grabadoras, toda esa incursión tecnológica reforzaba la emisión y circulación de una fuerte oralidad quechua y aymara que se imponía con aserción histórica -Xavier se refiere a este fenómeno como

\footnotetext{
15 Después de haber escuchado a Los Jairas en Europa, el cineaste alemán Werner Herzog considera incluir en Aguirre, la ira de Dios (Der Zorn Gottes, 1972) a un ejecutor de la zampoña. A comienzos de 1970, en Paris, inspirados por Los Jairas, surgen Los Inkas (conocidos también como Urubamba), que luego grabarían junto al compositor neoyorkino Paul Simon. La música andina había tomado cartas de ciudadanía en casi todo el mundo.

${ }^{16}$ Lo mismo habría sucedido cuando Yawar Mallku se proyectó en Francia. (Comunicación personal del escritor Jesús Urzagasti, que asistió en la filmación de esta película. En su novela En el país del Silencio (1987), un pasaje recoge este detalle del cine boliviano). Esta percepción reaparece en Bolivia, la vez más reciente en labios de una reina de belleza en el año 2003. El dato podría pertenecer a una historia-histeria que surge periódicamente.
} 
"canales expresivos" (1974, 101-132). Este giro de la tecnología, que multiplicaba también el acceso a pequeñas radios portátiles, alentaba la performatividad de la oralidad quechua y aymara (mucho después sería del guaraní y otras lenguas indígenas hasta entonces marginadas) y revelaba la intención de eliminar el analfabetismo en castellano, cuya rémora era aún notable en aquellos años 60 (sabemos que en Bolivia incluso hoy, leer no es un hábito).

\section{Perfil}

Xavier es jesuita y Bolivia, su patria adoptiva, estuvo convulsionada por los hechos político-sociales que resumí. Desde la reflexión actual, estábamos nada menos que al centro del auge de la Guerra Fría. Para esos primeros años de la década de los sesenta, otro jesuita, desde la tierra tensionada del Perú, surgió con una Teología de la Liberación, proposición que alentaba la militancia y el compromiso vivo con los sectores marginados de la sociedad que respiraba los efectos del gobierno popular de Velasco Alvarado. ${ }^{17}$ Se proponía una opción consciente de la humanidad pobre y descalificada, una práctica cristiana ecuménica y comprometida. ${ }^{18}$ Las tensiones políticas habían calado hondo.

Ya desde Santiago, en 1969, yo leía las producciones etno-sociológicas de un pequeño grupo de investigadores en Oruro que organizaron un centro de investigación llamado INDICEP (Instituto de Investigación Cultural para la Educación Popular). Eran revistas impresas con información etnográfica que me enviaban de Bolivia (posiblemente INDICEP) y se publicaban bajo la coordinación de Grover Vega, con patrocinio de las tempranas Iglesias de la Liberación, de procedencia canadiense ${ }^{19}$ que, con seguridad, llevaban a la práctica las lecciones de los talleres ofrecidos por Rodolfo Kusch. La antropología como carrera no existía en la Universidad Técnica de Oruro y hasta aquel entonces, por indirectas influencias del peruano Efraín Morote

\footnotetext{
$17 \mathrm{Mi}$ amigo y colega, el antropólogo Stefano Varese, en muestra de una antropología comprometida, asistió a ese gobierno (1968) redactando una ley que reconocía por vez primera el derecho inmemorial indígena a sus territorios en la Amazonía, especialmente los Asháninka. El tema lo vuelve a meditar Varese en su reciente Antropología del activismo y el arte del recuerdo (2018), especialmente en las páginas 127-160.

18 Sin duda, una reflexión del Concilio Vaticano II, que en palabras de Juan XXIII buscaba "abrir las ventanas para dejar entrar aire nuevo en la iglesia", se reconoce tempranamente en el pensamiento del teólogo Dietrich Bonhoeffer que sentía que su fe cristiana demandaba acción directa y, si fuera necesario, sacrificio ante la injusticia. Bonhoeffer era miembro de una célula rebelde de la resistencia que intentó asesinar a Hitler.

19 También Xavier lo apunta en Los mil rostros del quechua, 91.
} 
Best, se practicaba aquella especie de "folklorología" centrada en la performatividad de los danzarines del carnaval. Acompañaba esta folklorología una rica mitología local que alentaba un respeto práctico por las "tradiciones telúricas" -una especie de solapado reconocimiento de lo que ahora llamaríamos "pluriculturalidad", alentado por Alberto Guerra Gutiérrez, Amanda Zelaya, Nelly Blacutt, Augusto Beltrán Heredia, Julia Elena Fortún, Cristina Villanueva, y otrxs asociadxs con el Comité de Etnografía y Folklore, o Eduardo López Rivas, que se interesaba en una arqueología hecha en casa.

Como ya dijimos, el término "campesino" no recogía necesariamente la dimensión étnica del término porque aún respondía a las políticas estatales y asimilacionsitas del sindicalismo gastado del MNR, esmerado en campesinizar sin reconocer la coherencia aylluica en la antigua presencia de sociedades indígenas o las etnicidades andinas en Bolivia. Sin embargo, CIPCA, bajo la dirección de Xavier Albó, reposiciona la realidad étnica del país y se enfoca en privilegiar "el lado de la historia aymara". Esta inicial opción, quisiera pensar, estaba enmarcada en el renovado interés por documentar la tangible persistencia de sociedades étnicas que enfrentaba lentas transformaciones en la relación urbano-rural, en gran parte provocada por la implementación de la Reforma Agraria, que eliminaría el sistema de la hacienda y cuyas tierras se distribuirían, desigualmente, entre previos peones y asimismo antiguos hacendados que se convertían en "revolucionarios". ${ }^{20}$ CIPCA a través de sus estudios privilegia el lento aunque persistente proceso de migración del área rural hacia El Alto de La Paz, y las llamadas "zonas de colonización" en la Amazonía, la dinámica del cambio social y los nuevos escenarios adaptativos que motivaba la emergencia del aymara urbano y la paralela fundación de una ciudad-servicio de La Paz, con características propias, otro tema del enciclopédico interés de Xavier.

Así, su inicial y temprano proyecto sociolingüístico se fue transformando y ampliando, haciéndose verdaderamente inter-disciplinario a medida que la sociedad de su interés también cambiaba ante sus propios ojos. Los hablantes de idiomas nativos, después de los años setenta, vimos en las contribuciones académicas de Xavier un aliciente para continuar el trabajo que él había iniciado y sostenido. CIPCA es una institución boliviana en el pleno sentido de la palabra, como tal se adelantó en sus proposiciones que ligaron la praxis con la teoría, llevando a efecto sólidos proyectos que

\footnotetext{
20 El MNR distribuyó cinco millones de hectáreas (un cuarto de la superficie total de las haciendas) entre casi 153.000 familias.
} 
verdaderamente acompañan las innegables transformaciones que se dieron en Bolivia desde los años setenta hasta hoy en día. Xavier consolidó así toda una escuela, toda una institución, cuyo propósito define la relación teórica con la práctica y la búsqueda de soluciones tangibles. Su amplia obra se nota en la base de concretas políticas nacionales, directa o indirectamente. No hay investigadorx interesadx en Bolivia que no haya pasado por CIPCA, tarde o temprano tuvo que compartir diálogos de índole académica.

Bajo el patrocinio del Departamento de Antropología y el Instituto de Estudios Latinoamericanos de la Universidad de Texas en Austin, tuve la tarea de crear dos cursos centrados en el quechua, la sociolingüística, la traducción quechua-inglés y la etnología andina (1977-1979; 1985-87). Desechando la inopia de la lengua, en ese entonces produjimos programas grabados en el Laboratorio de Lenguas, siguiendo el texto titulado An Introduction to Spoken Bolivian Quechua, publicado por la Universidad de Texas (1969), con ricos materiales creados por los lingüistas Rudolph C. Troike, Garland D. Bills y Bernardo Vallejo C., un quechua-hablante del norte de Potosí y, anteriormente, por Marcelo Naranjo, un kichwa del area de Otavalo en el Ecuador, también lingüista. Gracias a la insistencia del antropólogo Richard P. Schaedel (19202005), primer director del Instituto de Estudios Latinoamericanos de la Universidad de Texas, Austin, mi amigo y mentor, el quechua afirmaba su lugar entre los Estudios Latinoamericanos en esa Universidad. Schaedel, a quien conocí en las oficinas de la OIT, la Organización Internacional del Trabajo, en Roma y Ginebra, insistía que quienes estudiaran el área andina debían estar compenetrados de sus lenguas indígenas y frecuentemente me recordaba que John V. Murra se había hecho etnohistoriador porque tuvo dificultades de comunicarse en quechua; no lo podía aprender.

Sin pensar dos veces, para entonces, ya tenía acceso al trabajo de Xavier Albó, a los de Joaquín Herrero y Jorge Urioste y los peruanos (como Alberto Escobar) que sostenidamente trabajan el quechua. También ya se podían emplear los trabajos de Louisa Stark, lo que me permitía ver al quechua ya no sólo como una lengua que se habla en Bolivia sino en todo el territorio que los inkas ocuparon en su expansión, por lo que se conoce a esa lengua como runasimi, lengua humana.

Así, siempre inspirado por las ideas y pasiones quechuistas de Xavier Albó, aunque ya muy lejos del estructuralismo inicial de sus trabajos, en 1997, mi colega John M. Schechter y yo organizamos una conferencia dedicada al quechua. Se llamó Arte Expresivo Quechua, y convocó a una generación de estudiosos del quechua y el aymara, de al menos veinte universidades del 
mundo. El propósito era caracterizar el antiguo territorio inka a través de las subyacentes formas expresivas del runasimi, desde Pasto en Colombia, hasta el norte de Chile y la Argentina, la Amazonía de habla quechua en Ecuador y Perú, atravesando "el macizo andino", aquel viejo concepto de Jaime Mendoza. El volumen que compilamos con los trabajos presentados en dicha conferencia dialogan inevitablemente con las ideas de Xavier. Sometido el texto a la crítica de las editoriales universitarias, muchas nos aceptaron, aunque después de un tiempo se retractaban porque no podían conseguir jueces que dictaminaran el contenido para poder publicarlo, pues todxs aquellxs que tenían las cualificaciones para juzgar el texto compilado y trilingüe (quechua, castellano, inglés, además de un capítulo en aymara) formaban parte del volume o estaban muy ocupadxs. Después de mucha espera, lo adoptó, finalmente, el Bonner Amerikanistische Studien de Bonn, ${ }^{21}$ aquella institución alemana dedicada a los estudios de sociedades indígenas en las Américas.

\section{Colofón}

Como se puede ver, el inicial interés y dedicación de Xavier Albó por los idiomas indígenas y específicamente el quechua, se multiplicó entre varixs influidxs e interesadxs por sus enseñanzas, y sus materiales se transformaron en lectura obligatoria en varias universidades 22 porque inspiraron un proceso de revitalización lingüística, abrieron serios diálogos colaborativos con otrxs investigadores, pero también guiaron, inspiraron y sistematizaron políticas públicas que acompañan los grandes procesos de los cambios históricos andinos, y no solo bolivianos. Si hoy en día sintonizamos la radio o vemos un programa televisivo, escucharemos la activa emisión de lenguas indígenas. Ese pequeño detalle de la biodiversidad humana que parece inocuo se debe, sin duda, al sostenido trabajo que Xavier Albó nos lega como una gran lección que rebasa las fronteras del país boliviano.

\footnotetext{
${ }^{21}$ El libro se publicó en 2004 con el título de Quechua Verbal Artistry/Arte Expresivo Quechua. Agradezco la colaboración de Sabine Dadenbach en contactar al Bonner Amerikanistische.

22 Desde 1965 muchas universidades en Europa, Israel, Japón, Francia, Inglaterra y los Estados Unidos abrieron cursos de quechua o aymara. En Cornell, Florida, Ohio, Pittsburgh, Michigan, Stanford, Texas, UCLA, UCDavis, se ha tratado de mantener estos programas que enfrentan, a menudo, problemas de financiamiento. Quienes estudian estos idiomas son en su mayoría lingüistas, estudiantes de antropología, ecólogos, literatos, futuros médicos e incluso biólogos.
} 
Intencionalmente, reconstruí mi versión de la década de los sesenta, pero la historia continúa su recorrer, saltando a esta segunda década del siglo XXI. Como es sabido, la Constitución Política del Estado Plurinacional boliviano (2009) reconoce entre sus leyes a las lenguas indígenas en igualdad de condiciones, siendo que el quechua es una de las lenguas indígenas cuya estructura lingüística precolombina se mantuvo casi intacta a través de los siglos. Es también una lengua indígena con el mayor número de hablantes de todas las que existen en las Américas entre cientas que palpitan. Para concluir, mi propósito ha sido el de rememorar la década de los años sesenta desde la perspectiva del estudiante de secundaria que fui, privilegiando el halo quechuista con que Xavier Albó nos afectaba al entregarnos sus primerizos estudios sobre el quechua. Vistos desde las décadas que nos trasladan hasta el año 2020, la contribución de Xavier Albó ha sido monumental, aquí quise señalar aquella vieja memoria y crónica de los años sesenta que, como se ha visto, me influyó directamente en ver y considerar el quechua con los ojos de la biodiversidad, en este caso, lingüística, que no los del prejuicio, la reticencia o el monolingüismo. Así el trabajo de altas convicciones que identifican a Xavier echó bases sólidas y fundantes para construir el gran Akapana que hoy se llama CIPCA, pero su influencia inspira y cubre, a través de su obra, a todos los lugares donde existen hablantes del runasimi, es decir, recorre el antiguo territorio que extendió Pachakuti IX hace más de cinco siglos, cruzando los Andes desde Pasto, en Colombia, hasta Tucumán, en la Argentina.

\section{Bibliografía Citada}

ALBÓ, Xavier. 1964. El quechua a su alcance. 2 vols. La Paz: Alianza para el Progreso.

---. $\quad$ 1974. Los mil rostros del quechua. Sociolingüística de Cochabamba. Lima: Instituto de Estudios Peruanos.

ARGUEDAS, José María. 1969. El sueño del Pongo. Santiago: Editorial Universitaria.

BILLS, Garland D., Bernardo Vallejo C.; and Rudolph C. Troike. 1969. An Introduction to Spoken Bolivian Quechua. Austin, TX: University of Texas Press.

BOUYSSE-CASSAGNE, Thérèse, Olivia Harris, Tristan Platt, Verónica Cereceda, comps. 1987. Tres reflexiones sobre el pensamiento Andino. La Paz: Hisbol.

CARTER, William E. 1964. Aymara Communities and the Bolivian Agrarian Reform. Gainesville, FLA: University of Florida Press. 
CERECEDA, Verónica. 1987. “Aproximaciones a una estética andina: de la belleza al Tinku". Tres reflexiones sobre el pensamiento andino. Thérèse Bouysse-Cassagne, Olivia Harris, Tristan Platt y Verónica Cereceda, comps. La Paz: HISBOL. 132-231.

DELGADO P., Guillermo y John Schechter, eds. 2004. Quechua Verbal Artistry. Arte Expresivo Quechua. Bonn: Bonner Amerikanistische Studien. Vol. 38.

ECHEVERRÍA, Evelio. 1972. “Un pueblo en guerra: La narrativa boliviana de 1960 a 1970". Nueva Narrativa Hispanoamericana 2(1): 159-167.

FREIRE, Paulo. 1967. Educação como prática da liberdade. Rio de Janeiro: Editõra Paz e Terra Ltda.

---. 2005 [1968]. Pedagogía del oprimido. México: Siglo XXI.

GREAVES, Thomas C., Xavier Albó, Godofredo Sandoval S. 1985. "Becoming a Tin Miner". Miners and Mining in the Americas. William W. Culver and Thomas C. Greaves, eds. Manchester: Manchester University Press. 171-191.

HOLMBERG, Allan R. 1960 [1950]. Nomads of the Long Bow. The Siriono of Eastern Bolivia. Chicago: The University of Chicago Press.

ILLICH, Ivan. 1970. Bolivia y la Revolución Cultural. La Paz: Cooperativa de Artes Gráficas Burillo.

LARA, Jesús, Ludwig Flachskamp und Hermann Trimborn. 1959. Volksdichtung der Ketschua. Berlin: Dietrich Reimer.

--- $\quad$ 1962. Sinchikay. Novela quechua. Buenos Aires: Platina.

--- $\quad$ 1965. LLalliypacha: tiempo de vencer. Novela quechua. Buenos Aires: Platina.

MARTÍNEZ SOTO-AGUILAR, Gabriel. 1975. Introducción a Isluga. Iquique: Depto. de Investigación, Sede Iquique. Universidad de Chile.

NOGALES GUZMÁN, Eduardo. 1994. “Yuyay jap'ina. Alfabetización intercultural bilingüe para la mujer andina". Presencia Literaria. La Paz, 23 de mayo. 11-12.

ORTIZ, Fernando. 2002 [1940]. Contrapunteo cubano del tabaco y el azúcar. Edición de Enrico Mario Santí. Madrid: Cátedra.

PORTUGAL MOLLINEDO, Pedro. 1989. “Una experiencia de organización política india". Textos Antropológicos 1(1): 103-115.

PRIMERA DECLARACIÓN DE BARBADOS: POR LA LIBERACIÓN DEL INDÍGENA. 1971. [http://servindi.org/pdf/Dec_Barbados_1.pdf] página descargada el 29 de noviembre 2019.

RIBERA DE LA SOUCHÈRE, Elena. 1968. "La guerrilla en Bolivia”. Nuevo Mundo 20. 43-50.

SALMÓN, Josefa, 2012. Decir Nosotros. En la encrucijada del pensamiento indianista. La Paz: Editorial Autodeterminación.

URIOSTE, Jorge y Joaquín Herrero. 1955. Gramática de la lengua quechua y vocabulario quechua-castellano, castellano-quechua de las voces más usuales. La Paz: Editorial Canata.

URZAGASTI, Jesús. 1987. En el país del Silencio. La Paz: Hisbol. 
VARESE, Stefano. 2018. Antropología del activismo y el arte del recuerdo. México: UNAM.

WACHTEL, Nathan. 1971. Los Vencidos. Los indios del Perú frente a la conquista española (1530-1570). Antonio Escohotado, trad. Madrid: Alianza.

New articles in this journal are licensed under a Creative Commons Attribution 4.0 United States License.

This journal is published by the University Library System of the University of Pittsburgh as part of its D-Scribe Digital Publishing Program, and is cosponsored by the University of Pittsburgh Press. 